\title{
Facilitation associated with three contrasting shrub species in heavily grazed pastures on the eastern Tibetan Plateau
}

\author{
P.-X. Li ${ }^{1,2}$, B. O. Krüsi ${ }^{3,5}$, S.-L. Li ${ }^{2}$, X.-H. Cai ${ }^{4}$ and F.-H. Yu ${ }^{1,6}$ \\ ${ }^{1}$ College of Nature Conservation, Beijing Forestry University, Beijing 100083, China \\ ${ }^{2}$ State Key Laboratory of Vegetation and Environmental Change, Institute of Botany, Chinese Academy of Sciences, \\ Beijing 100093, China \\ ${ }^{3}$ Swiss Federal Institute for Forest, Snow and Landscape Research, Zürcherstrasse 111, CH-8903 Birmensdorf, \\ Switzerland \\ ${ }^{4}$ Sichuan Academy of Forestry, 18 Xinghui West Road, Chengdu 610081, Sichuan, China \\ ${ }^{5}$ University of Applied Sciences Zürich-Wädenswil (ZHAW), Grüental Postfach 335, 8820 Wädenswil, Switzerland \\ ${ }^{6}$ Corresponding author.Tel \& Fax: +86 10 62336173.Email: feihaiyu@bjfu.edu.cn
}

Keywords: Grazing, High-altitude pasture, Potentilla fruticosa, Shrub-herb interaction, Sibiraea angustata, Spiraea alpina.

\begin{abstract}
Small-scale vegetation patterns are frequently the results of plant-plant interactions such as facilitation and competition. Facilitation should be particularly pronounced when both abiotic and biotic stresses are high, but few studies were conducted in such habitats. In heavily-grazed pastures on the eastern Tibetan Plateau, an area with both high abiotic stress and strong biotic disturbance, we made relevés of herb species both beneath and outside canopies of three shrub species (Spiraea alpina, Sibiraea angustata and Potentilla fruticosa) differing in palatability and canopy structure. Herb species richness $(S)$, pooled cover $(P C)$ of all species, number of flowering species $(F S)$ and number of inflorescences of all species $(I N)$ were greater outside than beneath the shrub canopies. Evenness $(J)$, in contrast, was smaller outside, while Shannon's diversity index $(H)$ was the same. Differences in $S$ and $J$ between plots beneath and outside the shrub canopies were greater in the case of $P$. fruticosa than in the cases of $S$. angustata and S. alpina, but differences in $P C, F S$ or $I N$ did not depend on the shrub species. Among the common species (frequency $\geq 6$ ), $47-85 \%$ were equally frequent beneath and outside the shrubs, $13-39 \%$ were more frequent outside and 3-13\% were more frequent beneath the shrubs. For the rarest species (frequency $<6$ ), however, more species occurred beneath than outside the shrubs. The ordination diagram showed a clear separation between the relevés outside and beneath the shrubs and a gradient from $P$. fruticosa via S. alpina to $S$. angustata, accompanied by a distinct decrease in the extent of the difference between the vegetation beneath and outside the shrub canopies. In conclusion, the three shrub species facilitated some species in the herb layer and each shrub species had a specific impact, related to its canopy structure and palatability but also to the grazing pressure, which was greater around the $P$. fruticosa shrubs than around $S$. alpina and $S$. angustata.
\end{abstract}

Nomenclature: Wu and Chen (2004).

\section{Introduction}

Facilitation and competition are key drivers for population dynamics, community structure and ecosystem functioning (Callaway 1992, 2007, Armas and Pugnaire 2005, Klanderud and Totland 2005, Begon et al. 2006, Yu et al. 2006, Arredondo-Núnez et al. 2009). Competition occurs in all types of habitats, while facilitation is most often found in harsh habitats with high abiotic stress and/or strong biotic disturbance (Bertness and Callaway 1994, Callaway et al. 2002, Callaway 2007). Facilitation and competition act simultaneously and the net effect depends at least partly on habitat quality (Bertness and Callaway 1994, Callaway and Walker 1997, Maestre et al. 2005). For instance, Callaway et al. (2002) found that competition dominated at lower elevations while facilitation prevailed at high elevations.

Environmental harshness can greatly limit plant distribution and development. For instance, only species that tolerate salinity can exist in high saline habitats, and heavy grazing can degrade vegetation by decreasing seed production, seedling establishment and growth of palatable species (Rousset and Lepart 2000, Callaway et al. 2002, 2005, Schütz et al. 2003, Bakker et al. 2004, Cipriotti and Aguiar 2005, Smit et al. 2006, 2007). Many studies have investigated the potential effects of facilitation in harsh habitats with either high abiotic stress (e.g., high soil salinity, low soil nutrients and low temperature; Belsky 1994, Verdú and García-Fayo 1996, Rousset and Lepart 2000, Callaway et al. 2002, Olofsson 2004) or strong biotic disturbance (e.g., heavy grazing and trampling; Olff et al. 1999, Rebollo et al. 2002, Bakker et al. 2004, Callaway et al. 2005), but few have investigated such effects in habitats with both high abiotic stress and strong biotic disturbance.

The heavily grazed grasslands which occupy about $35 \%$ of the Tibetan Plateau in southwestern China are ideally 
Table 1. Characteristics of the three shrub species and the surrounding grassland (i.e., the herb layer outside the shrub canopy) in heavily grazed pastures on the eastern Tibetan Plateau. Means $\pm 1 \mathrm{SE}$ are shown ( $\mathrm{n}=30$ for $S$. angustata and $S$. alpina shrubs, and $\mathrm{n}=40$ for $P$. fruticosa shrubs). For each variable, means sharing the same letters are not different at $P=0.05$ (by Duncan tests).

\begin{tabular}{llll}
\hline & Sibiraea angustata & Spiraea alpina & Potentilla fruticosa \\
\hline Palatability & Low & High & Intermediate \\
Shrub height $(\mathrm{cm})$ & $62.00 \pm 1.61^{\mathrm{a}}$ & $53.50 \pm 1.92^{\mathrm{b}}$ & $35.08 \pm 0.69^{\mathrm{c}}$ \\
Shrub canopy cover $(\%)$ & $60.17 \pm 2.42^{\mathrm{b}}$ & $87.50 \pm 1.41^{\mathrm{a}}$ & $85.52 \pm 1.21^{\mathrm{a}}$ \\
Herb layer height $(\mathrm{cm})$ & $16.50 \pm 0.39^{\mathrm{a}}$ & $16.03 \pm 0.34^{\mathrm{a}}$ & $7.50 \pm 0.20^{\mathrm{b}}$ \\
Herb layer cover $(\%)$ & $83.83 \pm 1.22^{\mathrm{a}}$ & $85.17 \pm 1.09^{\mathrm{a}}$ & $68.75 \pm 0.43^{\mathrm{b}}$
\end{tabular}

suited for such a study because both abiotic stress and biotic disturbance in this area are very high. Abiotic stress is primarily due to the high altitude of on average over $4000 \mathrm{~m}$. a.s.l., which is associated with short growing season, strong radiation and extreme temperature (Wang et al. 2002). Biotic disturbance in these high-altitude grasslands is due to widespread overgrazing (Wang et al. 2002, Song et al. 2006). In the grasslands, overgrazing and the ensuing land degradation (e.g., desertification) seem to be associated with an increased abundance of small shrubs such as Spiraea alpina, Sibiraea angustata and Potentilla fruticosa (Wang et al. 2002). Because of its importance for local and global biodiversity and its fragility and sensitivity to changes in climate and human activities, the Tibetan Plateau is a hot spot for ecological and evolutionary research (Wang et al. 2002, Yan et al. 2005, Song et al. 2006). Therefore, it will be very useful to better understand how the presence of shrubs affects the structure and function of the grassland vegetation. However, to date, very few studies have focused on plant-plant interactions and little is known about the associated effects on vegetation pattern and dynamics on the Tibetan Plateau (Song et al. 2006).

Here we report the results of shrub-herb interactions on the grasslands of the eastern Tibetan Plateau, which have been subjected to heavy grazing for several decades. We established same-sized circular plots both beneath and outside the canopies of three native shrub species, i.e., S. alpina, $P$. fruticosa and $S$. angustata, differing in palatability and canopy structure (canopy cover and height). In each plot we measured cover and counted number of inflorescences of each vascular species in the herb layer. Because on the Tibetan Plateau both abiotic and biotic conditions are very harsh, shrubs like S. alpina, P. fruticosa or S. angustata (in decreasing order of palatability) may facilitate survival and reproduction of the more palatable herb-layer species. We therefore expected that some herbaceous species occur and reproduce exclusively or preferentially beneath the canopies of these shrubs. We also expect that the facilitation effect differs among the three shrub species. Both palatability and canopy structure may affect the protective ability of the shrub species. Less palatable shrubs may have a larger capacity of facilitative protection again herbivores because they are less grazed and trampled. If protection from grazing is more important in the study system, then we expect that the facilitation effect is the largest in $S$. angustata, smallest in $S$. alpina and intermediate in P. fruticosa. On the other hand, higher canopy cover and lower stature of shrubs may impose stronger competition effects on the herbaceous species, which may reduce the chance to find a net facilitative effect. Thus, if competition is more important, then we expect that the facilitation effect will be most obvious in $S$. angustata, least in P. fruticosa and intermediate in $S$. alpina because $S$. angustata shrubs are the tallest with the sparsest canopy (Table 1).

\section{Materials and methods}

\section{Study area}

The study area is located on the eastern Tibetan Plateau in southwestern China, in Zoige County (102.10-103.55 E, 32.20-34.05 N, and 3400-3900 m.a.s.1.) of Sichuan Province. The climate is subalpine, continental and monsoonal with long winters and short springs and autumns. Mean annual precipitation is $650 \mathrm{~mm}$, and most (about $86 \%$ ) falls between May and October. The mean annual temperature ranges from 0.6 to $1.2^{\circ} \mathrm{C}$, with monthly averages of approximately $10^{\circ} \mathrm{C}$ during the warm and $-10^{\circ} \mathrm{C}$ during the cold seasons (Wang et al. 2002). The southwestern parts of Zoige County are occupied by wetlands, and the northeastern parts by dry grasslands, which are heavily grazed by livestock, mainly yaks and sheep. During the past 30 years these grasslands were severely overgrazed, stocking numbers exceeding the carrying capacity by more than 50\% (Wang et al. 2002, Zhou and Li 2003).

The study was conducted in two heavily grazed pastures, dominated by Poa spp., Kobresia spp. Polygonum spp., as well as by some native shrubs, including Spiraea mongolica, Spiraea alpina, Sibiraea angustata, Potentilla fruticosa, Cotoneaster horizontalis and Lonicera tibetica, which together covered $25-50 \%$ of the surface area. There were also some toxic plant species such as Anemone rivularis, Delphinium tongolense and Thalictrum alpinum var. elatum (Wang et al. 2002).

\section{Target shrubs}

For the present study, we selected three shrub species of the Rosaceae family, i.e., Spiraea alpina, Potentilla fruticosa and Sibiraea angustata. S. alpina and P. fruticosa are widely distributed in the high-altitude grasslands and $S$. angustata is endemic to the Tibetan Plateau (Wu 1998). They differ greatly in size, canopy structure, palatability, compound composition and other traits (Meng et al. 2003). Of the three 
shrub species, S. alpina is palatable for livestock, $P$. fruticosa less palatable and $S$. angustata unpalatable (Meng et al. 2003).

On the heavily-grazed alpine grasslands, S. alpina, $S$. angustata and $P$. fruticosa grow in patches up to several meters in diameter (Wang et al. 2002). These shrubs form the top vegetation layer, and based on the composition of the shrub layer two main pasture types are distinguished, i.e., the $S$. alpina-S. angustata type and the $P$. fruticosa type. In the $S$. alpina-S. angustata pasture, the shrubs cover about $50 \%$ of the surface area and the herbaceous layer is mainly formed by Epilobium palustre, Valeriana spp., Deschampsia caespitosa, Kobresia pygmaea and many other less common species. In the $P$. fruticosa pasture, shrubs cover about $25 \%$ of the area and Polygonum viviparum, Kobresia pygmaea, Gentiana squarrosa and Taraxacum tibetanum are the most common species in the herb layer (Wang et al. 2002).

The study was conducted in two pastures; one was the $S$. alpina-S. angustata type (the dominant shrubs species were $S$. alpina and S. angustata) and the other was the P. fruticosa type (the dominant shrubs species was $P$. fruticosa). The two pastures are about $15 \mathrm{~km}$ apart and similar with regard to climate and elevation.

\section{Field investigation}

During the summer of 2006, we randomly selected 30, 30 and 40 individuals of S. angustata, S. alpina and P. fruticosa, respectively. The selected shrubs were basically circular and with a diameter larger than $50 \mathrm{~cm}$. At each of the selected shrubs, two circular plots (= paired plots), with a diameter of $40 \mathrm{~cm}$ were established, one beneath the shrub canopy and the other $50 \mathrm{~cm}$ outside the edge of the canopy. Thus the sampling took a split-plot design, with shrub individuals (i.e., plot pairs) as the main plots and locations (beneath $v s$. outside shrub canopies) as the subplots. We used this design because vegetation commonly shows small-scale spatial heterogeneity, which may cover the effects of individual shrubs. We set up plot pairs associated with each selected shrub individual so that small-scale spatial heterogeneity could be largely avoided. We used circular plots with a diameter of about 40 $\mathrm{cm}$ because, if the plots were too small, only a few species could be sampled. We selected shrubs with a diameter larger than $50 \mathrm{~cm}$ because establishing circular plots of $40 \mathrm{~cm}$ in diameter was not possible in smaller shrubs. For each shrub, we visually estimated canopy cover and measured maximum height and two perpendicular crown diameters. For each circular plot, we visually estimated total vegetation cover in the herb layer as well as the cover of each vascular plant species, and counted the number of inflorescences for each species.

\section{Data analysis}

We calculated species richness ( $S$, number of species), pooled cover ( $P C$, the sum of the covers of all species), Shannon's diversity index $(H)$, evenness $(J)$, number of flowering species $(F S)$ and number of inflorescences of all species $(I N)$ in each plot, as well as frequency of occurrence and frequency of flowering of each species.

Shannon's diversity index was calculated as $H=-\Sigma p_{i} \ln p_{i}$ $(i=1,2 \ldots S)$, where $S$ is the number of species and $p_{i}$ is the cover of species $i$ divided by the cumulative cover of all species in a plot. Evenness was derived as $J=H / H_{\max }=H / \ln S$ (Kent and Coker 1992).

We used one-way ANOVA followed by Duncan tests to compare differences of the characteristics among the three shrub species. We employed a split-plot model to analyze data on $S, P C, H, J, F S$ and $I N$. Plot pairs were treated as whole plots, shrub species as a whole plot factor and plot location (beneath and outside shrub canopy) as a subplot factor (Scheiner and Gurevitch 2001). Chi-square tests were used to investigate the difference in frequency of the more common species (pooled frequency $\geq 6$ ) between plots beneath and outside shrub canopies.

To investigate whether the herb-layer vegetation composition of the six combinations of shrub species by location could be distinguished, we analyzed the relevés by principal coordinates analysis (PCO) with the software MULVA-5 (Wildi and Orlóci 1996). Prior to analysis, the data were square root transformed.

\section{Results}

\section{Morphological traits of the target shrubs}

Canopy cover of the palatable S. alpina and P. fruticosa did not differ, but they were significantly greater than that of the unpalatable $S$. angustata (Table 1). Shrub height was the largest in S. angustata, smallest in P. fruticosa and intermediate in S. alpina. Outside the shrub canopies, height and cover of the herb layer were significantly greater around the $S$. alpina and S. angustata shrubs than in the over-grazed $P$. fruticosa pasture (Table 1), suggesting that grazing pressure was greater in the $P$. fruticosa pasture than in the $S$. alpina-S. angustata pasture.

\section{Diversity, pooled cover and reproduction}

Species richness $(S)$ both beneath and outside the shrub canopies was much lower in $P$. fruticosa than in S. alpina and $S$. angustata (Table 2; Fig. 1). Across the two locations $P C$, $H$ and $J$ were all larger in $S$. alpina and S. angustata, and FS did not differ among them (Table 2; Fig. 1). However, $I N$ was significantly larger in P. fruticosa.

Generally, $S, P C, F S$ and $I N$ were larger outside than beneath canopies, $H$ did not differ and $J$ was larger beneath the canopy (Fig. 1; Table 2). Such locational differences in $S$ and $J$ were more pronounced in the cases of $P$. fruticosa than in $S$. angustata and S. alpina (Fig. 1; Table 2, significant interaction effect). Regarding $P C, F S$ or $I N$, however, the locational differences did not depend on the shrub species (Fig. 1; Table 2, the interaction effect: $P>0.05$ ). 
Table 2. Effects of shrub species and plot location (beneath $v s$. outside the shrub canopy) on the community-level traits of the herb layer. $F$-values, degree of freedom (DF) and the significance levels $\left({ }^{* * *} P<0.001,{ }^{* *} P<0.01,{ }^{*} P<0.05\right.$ and $\left.{ }^{\mathrm{ns}} \mathrm{P} \geq 0.05\right)$ are based on two-way repeated measures ANOVA with plot location as the repeated variable. $S$ - richness, $P C$ - pooled cover of all plant species, $H$ - Shannon's diversity index, $J$ - evenness, $F S$ - number of flowering species and $I N$ - number of inflorescences.

\begin{tabular}{|c|c|c|c|c|c|c|c|}
\hline Effect & DF & $s$ & $P C$ & $H$ & $J$ & FS & IN \\
\hline Shrub species & 2,97 & $112.48^{\text {max }}$ & $36.27^{x+1}$ & $94.79^{x+m}$ & $21.92^{\text {nath }}$ & $0.23^{\text {ns }}$ & $4.55^{x}$ \\
\hline Plot location & 1,97 & $96.98^{* * t}$ & $653.72^{\text {t.t.t}}$ & $0.02^{\mathrm{ns}}$ & $66.24^{\text {trtx }}$ & $9.00^{*}$ & $42.45^{\text {tzt }}$ \\
\hline Species $\times$ Location & 2,97 & $3.29^{*}$ & $0.87^{\mathrm{ns}}$ & $2.68^{\mathrm{ns}}$ & $14.43^{\text {ktz }}$ & $0.54^{\mathrm{ns}}$ & $2.15^{\mathrm{ns}}$ \\
\hline
\end{tabular}
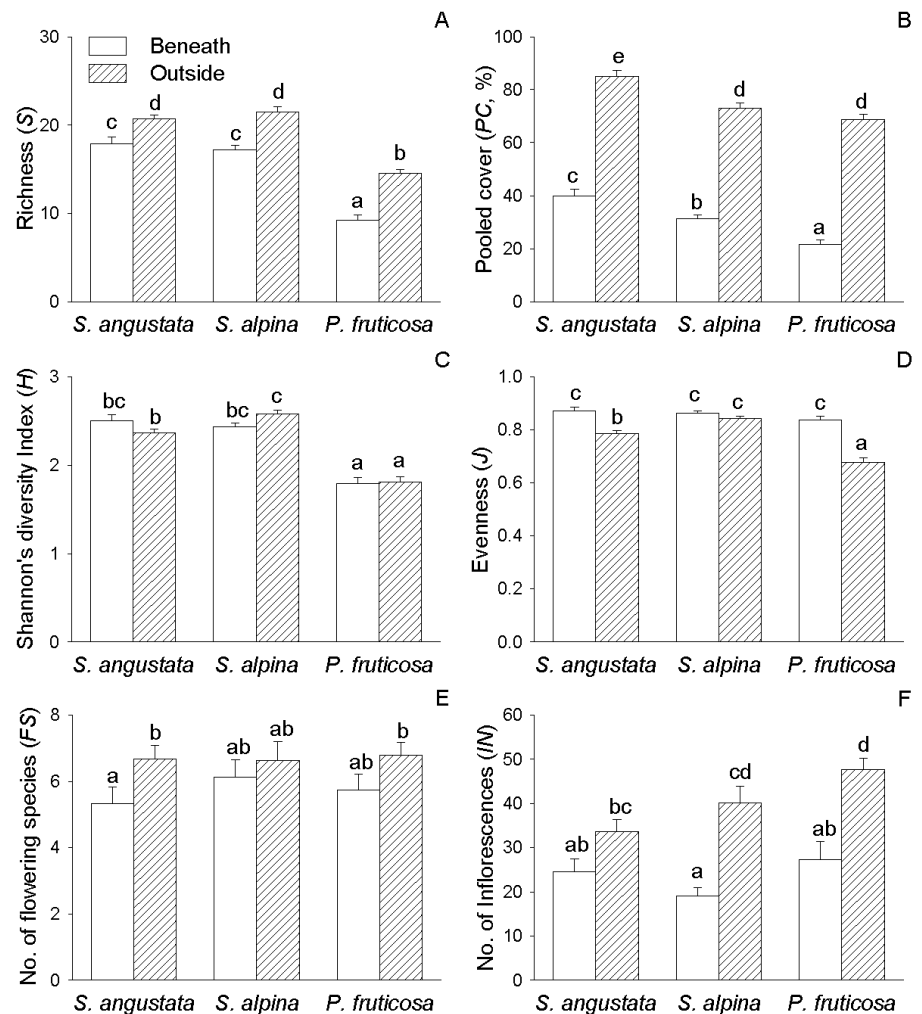

Figure 1. Average species richness (A), pooled cover of all species (B), Shannon's diversity index (C), evenness (D), number of flowering species (E) and number of inflorescences of all species $(F)$ in plots beneath and outside the canopies of the three shrub species. Bars and vertical lines stand for means and standard errors. Bars sharing the same letters are not different at $P=0.05$ (by Duncan tests).

\section{Frequencies of occurrence and flowering}

Overall species number in the circular plots beneath and outside the shrubs of $S$. angustata, S. alpina and P. fruticosa was fairly comparable, with 53, 55 and 59 vascular plant species, respectively (Table 3, App. 1-4).

On the 60 plots beneath and outside the $S$. angustata shrubs, 40 species were recorded six times or more. Of these 40 species, five occurred more and one (Trisetum spicatum) less often outside than beneath the $S$. angustata shrubs (Table 3). One (Saussurea stella) occurred exclusively outside but none occurred exclusively beneath the shrubs. Five species flowered more and one less frequently outside than beneath the canopies (Appendix 1).

On the 60 plots associated with the $S$. alpina shrubs, 41 species were recorded six times or more (Appendix 2). Of these, ten species occurred more and two (Poa pratensis and
Ajania tenuifolia) less frequently outside than beneath the shrubs. One species (Poa pratensis) occurred exclusively beneath and none occurred exclusively outside the the canopies of $S$. alpina (Appendix 2). Eleven species reproduced more and three less often outside than beneath S. alpina (Appendix 2). Of the latter three, Leontopodium wilsonii was especially noteworthy because not the occurrence ( 27 beneath $v s .22$ outside) but only the reproduction was facilitated by $S$. alpina shrubs (flowering frequency: 16 beneath $v$ s. 5 outside).

In the 80 plots beneath and outside the P. fruticosa shrubs, 38 species were recorded six times or more. Out of these, 15 occurred more and five (Ajania tenuifolia, Anaphalis spp., Allium condensatum, Poa annua and Taraxacum tibetanum) less often outside than beneath the shrubs (Appendix 3). Three species occurred exclusively outside and two (P. annua and Anaphalis spp.) exclusively beneath the shrubs. Five species reproduced more and four less fre- 
Table 3. Absolute number $(A N)$ and relative value $(R \%)$ of the more common (frequency $\geq 6$ ) and the rarest (frequency $<6)$ herb layer species that respond (A) preferably, (B) indifferently or (C) non-preferably to the presence of the three studied shrub species, according to the data presented in Appendices 1-4.

\begin{tabular}{|c|c|c|c|c|c|c|}
\hline \multirow[t]{2}{*}{ Species } & \multicolumn{2}{|c|}{ Sibiraea angustata } & \multicolumn{2}{|c|}{ Spiraea alpina } & \multicolumn{2}{|c|}{ Potentilla fruticosa } \\
\hline & AN & $\mathrm{R} \%$ & AN & $\mathrm{R} \%$ & AN & $\mathrm{R} \%$ \\
\hline \multicolumn{7}{|c|}{ More common species(frequency $\geq 6$; differences statistically significant) } \\
\hline (A) Preferable (beneath > outside) & 1 & 2.5 & 2 & 4.9 & 5 & 13.1 \\
\hline (B) Indifferent (beneath = outside) & 34 & 85.0 & 29 & 70.7 & 18 & 47.4 \\
\hline (C) Non-preferable (beneath < outside) & 5 & 12.5 & 10 & 24.4 & 15 & 39.5 \\
\hline Total & 40 & 100 & 41 & 100 & 38 & 100 \\
\hline
\end{tabular}

Rarest species (frequency <6; differences not statistically tested)

\begin{tabular}{lllllll} 
(A) Preferable (beneath > outside) & 4 & 30.8 & 9 & 64.3 & 14 & 66.6 \\
(B) Indifferent (beneath = outside) & 3 & 23.1 & 2 & 14.3 & 1 & 4.8 \\
(C) Non-preferable (beneath < outside) & 6 & 46.1 & 3 & 21.4 & 6 & 28.6 \\
Total & 13 & 100 & 14 & 100 & 21 & 100 \\
\hline
\end{tabular}

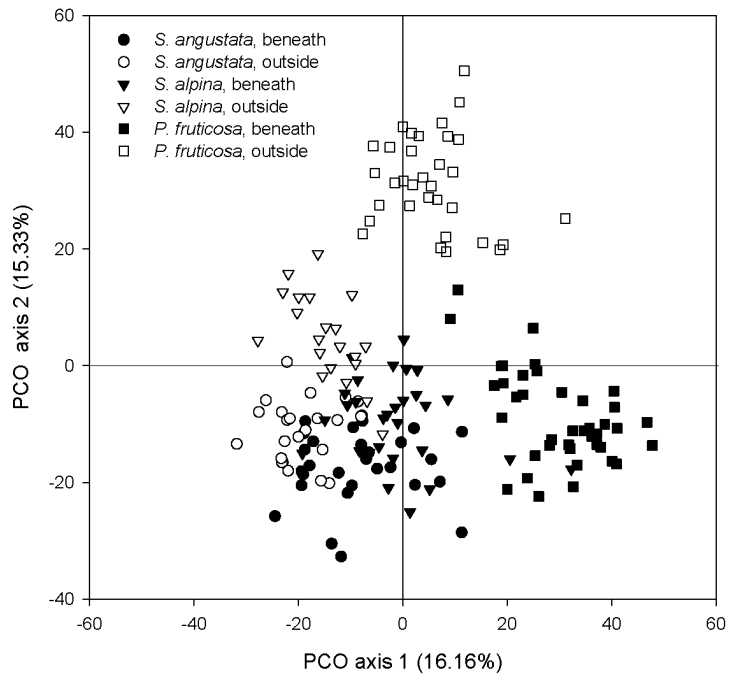

Figure 2. Ordination of the relevés by Principal Coordinates Analysis (PCO). All 73 species were included in the analysis. Sample sizes (n) for each community-location combination were 30, 30 and 40 for Sibiraea, Spiraea and Potentilla, respectively.

quently outside than beneath the $P$. fruticosa shrubs (Appen$\operatorname{dix} 3)$.

The locational differences between plots beneath and outside the shrubs increased from S. angustata, via S. alpina, to $P$. fruticosa, as indicated by the decrease from 85.0 to 70.7 and $47.4 \%$, respectively, of the proportion of the more common herb-layer species that are equally frequent beneath and outside the canopies of the studied shrubs (Table 3 ).

Regarding the rarest species (pooled frequencies $<6$; App. 4), according to a simple sign analysis, most of them were more frequent beneath the shrubs $(30.8,64.3$ and $66.6 \%$ for $S$. angustata, S. alpina and P. fruticosa, respectively), a fair percentage (46.1, 21.4 and $28.6 \%$, respectively) more frequent outside and only few $(23.1,14.3$ and 4.8\%, respectively) indifferent (Table 3).

\section{Vegetation ordination}

In the ordination diagram, the relevés of the six combinations of location by shrub species formed fairly recognizable groups (Fig. 2). There were clear differences with regard to both shrub species (axis 1, explaining $16.2 \%$ of the variance) and location (beneath vs. outside; axis 2, 15.3\%). The locational difference in the herb layer vegetation was the largest in $P$. fruticosa, and also significant for $S$. alpina but not for S. angustata (Fig. 2).

\section{Discussion}

To our knowledge, this study is the first paired-plot investigation on shrub-herb interactions on the Tibetan Plateau, where both abiotic stress and biotic disturbance are very high. We found marked differences in species occurrence and diversity between plots beneath and outside the canopies of the three shrub species. Also, many of the observed differences clearly depended on the shrub species. On the whole, these findings on the Tibetan Plateau are in agreement with the results of comparable studies from other habitats in different parts of the world (Olofsson 2004, Klanderud and Totland 2004, 2005, Yu et al. 2006).

\section{Frequency of occurrence and flowering}

Most of the common species (frequency $\geq 6$ ) did not depend on the presence of the shrubs, a fair percentage was more frequent outside and only few were clearly more frequent beneath the shrubs (Table 3, Appendices 1-4). Most of the rarest species (frequency $<6$ ), by contrast, were more frequent beneath the shrubs (Table 3; App. 4). The fact that some species occurred and/or reproduced exclusively or preferentially beneath the shrub canopies suggests a dominant shrub-mediated facilitation effect on these species. Regarding the species which occurred exclusively or predomi- 
nantly outside the shrub canopies, we assume that they cannot tolerate shading and/or root competition for nutrients and/or water. On the whole, species that preferred microsites beneath the shrub canopies should be more palatable, less tolerant to grazing, taller and more tenuous and more shade-tolerant, whereas those that preferred micro-sites outside the shrub canopies were less palatable, more tolerant to grazing, smaller and less shade-tolerant (Callaway 1992, Rebollo et al. 2002, Bakker et al. 2004). The protection from trampling and grazing seems to facilitate grazing-sensitive species, while the amelioration of microenvironment seems to facilitate the more shade-tolerant species. However, it is difficult to distinguish the two types of facilitation.

For most species, frequencies of flowering and frequency of occurrence were closely and positively correlated (Appendices 1-3). However, a few species such as Leontopodium wilsonii in the $S$. alpina pasture and Lancea tibetica in the $P$. fruticosa pasture were equally frequent beneath and outside shrub canopies but they flowered more extensively beneath the shrubs, suggesting reproductive facilitation (Callaway and Walker 1997, Rebollo et al. 2002, Tielbörger and Kadmon 2000, Bakker et al. 2004, Armas and Pugnaire 2005). Due to heavy grazing by livestock, reproduction for these species is mostly not possible in the pasture outside the shrubs, which may restrict the development of the genetic variability within the population and thus make the population less variable in the long run. For these species, therefore, the generatively reproducing individuals beneath the shrubs can potentially serve as a seed source to the part of the population outside the shrubs to sustain its viability. Therefore, reproductive facilitation by shrubs can potentially be crucial for the long-term survival of the part of the population living on the heavily grazed pastures outside the protective canopies of the shrubs where seed production is mostly not possible (Oesterheld and Oyarzábal 2004).

\section{Species diversity, composition and reproduction at community level}

Overall species number in plots associated with the shrubs of S. angustata, S. alpina and P. fruticosa was fairly comparable (Table 3; App. 1-4). Ordination analysis revealed, however, a clear vegetation gradient from $S$. angustata via S. alpina to P. fruticosa and also a clear separation between the small relevés outside and beneath the shrubs (Fig. 2). The gradient from $S$. angustata via $S$. alpina to $P$. fruticosa was in addition accompanied by a distinct increase in the extent of locational difference. Even though the three shrub species were able to provide facilitation via protection against grazing, most of the community parameters were not higher but lower beneath than outside the shrubs (Fig. 1). Most likely, this can be explained by the shrub-related competition for light and possibly also water and/or nutrients, which was particularly severe beneath the dense and low-sitting canopies of $P$. fruticosa. Part of the locational difference can be attributed to facilitation, i.e., to the exclusive or preferential presence beneath the shrub canopies of some graz- ing-sensitive species. However, most of the locational differences were due to the grazing-tolerant species that grew exclusively or mostly outside the shrub canopies (del Moral 1983, Rebollo et al. 2002, Bakker et al. 2004, Klanderud and Totland 2004). This is in line with the observations of Wang et al. (2002) who reported for the wider study area (i.e., Zoige County) that over-grazing led to an increase in abundance and diversity of species that are toxic to livestock (mostly from the families of Ranunculaceae and Compositae). Even on the climatically harsh and frequently over-grazed Tibetan Plateau, therefore, the negative impacts of shrubs on smallscale floristic richness of the herb layer far outweighed their positive facilitation-related effects.

While small-scale species diversity was significantly greater outside the shrub canopies, the reverse was the case for evenness, indicating more homogeneous vegetation beneath (Fig. 1). Most likely, this was probably due to the absence of selective grazing beneath the canopies, which is known to favor unpalatable and toxic species that, in addition, often form fairly large patches, cushions or tussocks. This agrees with the observation of Yan et al. (2005) who found on alpine grasslands in the Tibetan Plateau that plants tended to be more equally present on lightly than on heavily grazed areas, implying that moderate levels of disturbance maximize species evenness. This view is supported by studies from other parts of the world (Rebollo et al. 2002, Cipriotti and Aguiar 2005). In the present study, evenness was greatest beneath the unpalatable $S$. angustata shrubs and smallest on the over-grazed plots outside the $P$. fruticosa shrubs, suggesting again that very little disturbance may have a negative effect on evenness.

The locational differences in species richness were clearly greater in P. fruticosa shrubs than in S. angustata and $S$. alpina (Fig. 1). In the ordination space, correspondingly, the relevés taken beneath and outside the $P$. fruticosa shrubs were more clearly separated from each other than the corresponding sets of relevés from the S. alpina and S. angustata shrubs (Fig. 2). We presume that the above-mentioned differences were due to both traits of the shrub species and differences in grazing pressure, which, in turn, may be linked to the shrub species again. Due to the canopy structure, for instance, light supply beneath the low $P$. fruticosa shrubs was clearly more limited than beneath the tall S. alpina and $S$. angustata shrubs. Lack of light reduced the overall cover of the herb layer as well as the number of species that could potentially grow there (Facelli and Temby 2002, Bossuyt et al. 2005, Gómez-Aparicio et al. 2005).

\section{Conclusions}

In conclusion, on the Tibetan Plateau shrubs can facilitate species in the herb layer, with regard to frequency of both occurrence and flowering. The number of facilitated species increased with the shrub's protective capacity. For the latter morphological features (such as closeness to the ground and density of the canopy) rather than unpalatability seemed crucial. Different shrub species protected different kinds and 
numbers of vascular species. For the facilitated herb layer species, the effect may be stage-specific, affecting primarily growth or sexual reproduction. Further and preferably experimental studies are needed to elucidate the underlying mechanisms of such shrub-herb-interactions.

Acknowledgements: We thank Mrs. M. Zhang, H. Li and Q. Zhang for help during the field investigation, Dr. Q. Wang for specimen identification and three reviewers for valuable comments on an earlier version of the manuscript. This research was supported by NSFC (31070371) and the Forestry Commonwealth Program (201004078).

\section{References}

Armas, C. and F.I. Pugnaire. 2005. Plant interactions govern population dynamics in a semi-arid plant community. J. Ecol. 93:978-989.

Arredondo-Núñez, A., E.I. Badano and R.O. Bustamante. 2009. How beneficial are nurse plants? A meta-analysis of the effects of cushion plants on high-Andean plant communities. Соттиnity Ecol. 10:1-6.

Bakker, E.S., H. Olff, C. Vandenberghe, K. De Maeyer, R. Smit, J.M. Gleichman and F.W.M. Vera. 2004. Ecological anachronisms in the recruitment of temperate light-demanding tree species in wooded pastures. J. App. Ecol. 41:571-582.

Begon, M., C.R. Townsend and J.L. Harper. 2006. Ecology: from Individuals to Ecosystems, 4th edn. Blackwell, Oxford.

Belsky, A.J. 1994. Influences of trees on savanna productivity: Tests of shade, nutrients, and tree-grass competition. Ecology 75:922932.

Bertness, M.D. and R.M. Callaway. 1994. Positive interactions in communities. Trends Ecol. Evol. 9:191-193.

Bossuyt, B., B. de Fré and M. Hoffmann. 2005. Abundance and flowering success patterns in a short-term grazed grassland: early evidence of facilitation. J. Ecol. 93:1104-1114.

Callaway, R.M. 1992. Effect of shrubs on recruitment of Quercus douglasii and Quercus lobata in California. Ecology 73:21182128.

Callaway, R.M. 2007. Positive Interactions and Interdependence in Plant Communities. Springer, Dordrecht.

Callaway, R.M., R.W. Brooker, P. Choler, Z. Kikvidze, C.J. Lortie, R. Michalet, L. Paolini, F.I. Pugnaire, B. Newingham, E.T. Aschehoug, C. Armas, D. Kikodze and B.J. Cook. 2002. Positive interactions among alpine plants increase with stress. $\mathrm{Na}$ ture 417:844-848.

Callaway, R.M., D. Kikodze, M. Chiboshvili and L. Khetsuriana. 2005. Unpalatable plants protect neighbors from grazing and increase plant community diversity. Ecology 86:1856-1862.

Callaway, R.M. and L.R. Walker. 1997. Competition and facilitation: a synthetic approach to interactions in plant communities. Ecology 78:1958-1965.

Cipriotti, P.A. and M.R. Aguiar. 2005. Interspecific competition interacts with the spatial distribution of a palatable grass to reduce its recruitment. Rangeland Ecol. Manage. 58:393-399.

Facelli, J.M. and A.M. Temby. 2002. Multiple effects of shrubs on annual plant communities in arid lands of South Australia. Austral. Ecol. 27:422-432.

Gómez-Aparicio, L., F. Valladares, R. Zamora and J.L.Quero. 2005. Response of tree seedlings to the abiotic heterogeneity gener- ated by nurse shrubs: an experimental approach at different scales. Ecography 28:757-768.

Kent, M. and P. Coker. 1992. Vegetation Description and Analysis. Belhaven, London.

Klanderud, K. and Ø. Totland. 2004. Habitat dependent nurse effects of the dwarf-shrub Dryas octopetala on alpine and arctic plant community structure. Ecoscience 11:410-420.

Klanderud, K. and Ø. Totland. 2005. The relative importance of neighbours and abiotic environmental conditions for population dynamic parameters of two alpine plant species. J. Ecol. 93:493501.

Maestre, F.T., F. Valladares and J.F. Reynolds. 2005. Is the change of plant-plant interactions with abiotic stress predictable? A meta-analysis of field results in arid environments. J. Ecol. 93:748-757.

Meng, H.J., A.H. Pan and Z.Q. Chang. 2003. Analysis of feeding value of several forage shrubs in Qilian Mountain. J. Gansu Forest Sci. Tech. 28:11-14.

del Moral, R. 1983. Competition as a control mechanism in subalpine meadows. Am. J. Bot. 70:232-245.

Oesterheld, M. and M. Oyarzábal. 2004. Grass-to-grass protection from grazing in a semi-arid steppe. Facilitation, competition, and mass effect. Oikos 107:576-582.

Olff, H., F.W.M. Vera, J. Bokdam, E.S. Bakker, J.M. Gleichman, K. de Maeyer and R. Smit. 1999. Shifting mosaics in grazed woodlands driven by the alternation of plant facilitation and competition. Plant Biol. 1:127-137.

Olofsson, J. 2004. Positive and negative plant-plant interactions in two contrasting arctic-alpine plant communities. Arct. Antarct. Alp. Res. 36:464-467.

Rebollo, S., D.G. Milchunas, I. Noy-Meir and P.L.Chapman. 2002. The role of a spiny plant refuge in structuring grazed shortgrass steppe plant communities. Oikos 98:53-64.

Rousset, O. and J. Lepart. 2000. Positive and negative interactions at different life stages of a colonizing species (Quercus humilis). $J$. Ecol. 88:401-412.

Scheiner, S.M. and J. Gurevitch (eds.) 2001. Design and Analysis of Ecological Experiments, 2nd edn. Oxford University Press, Oxford.

Schütz, M., A.C. Risch, E. Leuzinger, B. Krüsi and G. Achermann. 2003. Impact of herbivory by red deer (Cervus elaphus L.) on patterns and processes in subalpine grasslands in the Swiss National Park. Forest Ecol. Manage. 181:177-188.

Smit, C., M. Gusberti and H. Müller-Schärer. 2006. Safe for saplings; safe for seeds? Forest Ecol. Manage. 237:471-477.

Smit, C., C. Vandenberghe, J. den Ouden and H. Müller-Schärer. 2007. Nurse plants, tree saplings and grazing pressure: changes in facilitation along a biotic environmental gradient. Oecologia 152: 265-273.

Song, M.H., Y.Q Tian, X.L. Xu, Q.W. Hu and H. Ouyang. 2006. Interactions between root and shoot competition among four plant species in an alpine meadow on the Tibetan Plateau. Acta Oecol. 29:214-220.

Tielbörger, K. and R. Kadmon. 2000. Indirect effects in a desert plant community: is competition among annuals more intense under shrub canopies? Plant Ecol. 150:53-63.

Verdú, M. and P. García-Fayos. 1996. Nucleation processes in a Mediterranean bird-dispersed plant. Funct. Ecol. 10:275-280.

Wang, Q., W.K. Bao, Z.L. Yan, T. Kumpula, A. Colpaert and A. Manderscheid. 2002. Basic types and characteristics of the west- 
ern Zoige Meadows and their changes in recent decades. Chin. J. App. Environ. Biol. 8:133-141.

Wildi, O. and Orlóci, L. 1996. Numerical Exploration of Community Patterns: A Guide to the Use of MULVA-5. $2^{\text {nd }}$ edn. SPB Academic Publishing, Amsterdam.

Wu, N. 1998. The community types and biomass of Sibiraea angustata scrub and their relationship with environmental factors in Northwestern Sichuan. Acta Bot. Sin. 40:860-870.

Wu Z. Y. and Chen X. Q. 2004. Flora of China. Science Press, Beijing.

Yan, Y., Y.Y. Zeng, J.H. Zhang, J.G. Zhang and X.H. Zhong. 2005. Diversity of plant species of alpine grassland in Nakchu of Tibet, China. J. Wuhan Univ. 10:659-664.

Yu, F.H., B. Krüsi, M. Schütz, J. Schneller and O.Wildi. 2006. Is vegetation beneath Carex sempervirens tussocks highly specific or an image of the surrounding vegetation? J. Veg. Sci. 17:477486.

Zhou, G.J. and H. Li. 2003. Research on the reasons for desertification and countering measures on Zoige Grasslands. J. Sichuan Grassl. 1:35-36.

Received January 13, 2010 Accepted December 5, 2010

\section{Appendices}

The files may be downloaded from the web site of the publisher at www.akademiai.com.

Appendix 1. Frequencies of occurrence and flowering of the more common species (pooled frequency $\geq 6$ ) and $\chi^{2}$ of the effect of plot location (beneath $v$ s. outside canopies of the $\mathrm{Si}$ biraea angustata shrubs, $\mathrm{n}=30) .{ }^{* * *} P<0.001,{ }^{* *} P<0.01$ and $P<0.05$.

Appendix 2. Frequencies of occurrence and flowering of the more common species (pooled frequency $\geq 6$ ) and $\chi^{2}$ of the effect of plot location (beneath vs. outside canopies of the Spiraea alpina shrubs, $\mathrm{n}=30) .{ }^{* * *} P<0.001,{ }^{* *} P<0.01$ and $P<0.05$

Apendix 3. Frequencies of occurrence and flowering of the more common species (pooled frequency $\geq 6$ ) and $\chi^{2}$ of the effect of plot location (beneath $v s$. outside canopies of the $P o$ tentilla fruticosa shrubs, $\mathrm{n}=40) .{ }^{* * *} P<0.001,{ }^{* *} P<0.01$ and ${ }^{*} P<0.05$.

Appendix 4. Frequency of the species with fewer than six occurrences in plots beneath and outside the shrub canopies of (A) Sibiraea angustata $(\mathrm{n}=30)$, (B) Spiraea alpina $(\mathrm{n}=30)$ and (C) Potentilla fruticosa $(\mathrm{n}=40)$. 